\title{
The illegitimate children parentage
}

\author{
Arezo Rashidi \\ Department of Education, Jurisprudence and Principles Orientation, Sanandaj City, Kurdistan, Iran \\ E-mail address: Arezoo.rashidi92@gmail.com
}

\begin{abstract}
Parentage is linking something to something else. Linkage is of two types: 1. Longituidinal linkage like donation between fathers and sons. 2. Laternal linkage like a donation as between sisters and aunts. So parentage is an infinitive, meaning relationship, kinship, and interest between two things. In Farsi, it is called lineage and French apply the word "filation" as meaning continuity, chain, generation, seed, successiveness, cohesion and subsequent things, coming after one another. Scholars and lawyers have provided various definitions. So, parentage means the birth of a person from a mother created by way of lawful marriage or by the possession of a woman for a man or by way of uncertainty, i.e. a person with a specific father or that the birth of two peoples out of one origin.
\end{abstract}

Keywords: Parentage; Longitudinal linkage; Lateral linkage

\section{INTRODUCTION}

In another definition, parentage is the leading of the birth of someone, another like father and son or the leading of the birth of two people to the third party like two brothers of one father (Najafi, 1981). Parentage is a blood and legal relationship relating parents to their children. This means the father-child or mother - child relationship that includes not kinsmen in the outside line (Katoozian, 1993).

Linkage is of two types:

1. Longituidinal linkage like donation between fathers and sons

2. Laternal linkage like a donation as between sisters and aunts

\section{TYPES OF PARENTAGE}

In the Iranian law, articles 1021, 1161 have mentioned discussions related to relationship and descendants. Hence, parentage can be divided into various forms such as special and general parentage or parentage out of marriage and parentage without marriage.

\section{1. Special and general parentage}

A) Special parentage: The concept of this type of parentage could b sought in articles 1158 to 1167 . On the basis of these articles, parentage is defined as: the true blood relationship 
and interest existing between two peoples where one is born as a result of birth from loin and the other is born directly (Safaee \& Emami, 1995).

B) General parentage: According to article. 1031, onwards, and 1158 of civil law, general parentage is defined as the true blood relationship and interest existing between two peoples where one is born as a result of birth from loin or the latter's womb or as a result of the birth of two people from the third party (Safaee \& Emami, 1995).

In fact the general parentage is the same as relative relationship which is of types predicted that exists in articles 1995, onwards civil law. Although the Iranian civil law has introduced relative relationship, parentage and descendants in different topics, i.e. the Iranian civil law has brought relative relationship in the sixth book and parentage and descendants in the eight book after marriage and divorce while speaking of it as under the title of family only through the Obligation to express unanimously, the interdependence relationship contents on the general concept with the issues of the family and marriage in such a way that is imperative relationship an parentage be discussed following family, marriage and divorce.

\section{2. Parentage out of marriage and without marriage}

In another grouping, parentage could be examined with respect to the quality of the infant's birth. In other words, the infant is born as a result of marriage and matrimony of his parents and sometimes without the matrimonial relationship being ever established, the infant is born, put it simply, the semen of the newborn is conceived without marriage.

\section{A) Parentage out of marriage}

This type of parentage is the common type of parentage which is the fruit of legal and valuable institution of marriage. It is established by the way of matrimonial bond between the husband and the wife. This type of parentage is usually examined under the title of legitimate parentage while articles 1158,1159 of civil law provide for such conditions.

\section{B) Parentage without marriage}

It is obvious that contrary to the previous items, the infant is born out of the marriage context and there's been no matrimonial bond between the couples' semen. Of course, person without marriage is sometimes legitimate like parentage caused by uncertainty and is sometimes illegitimate and thus, has been considered in the holy Islamic teachings as well as the civil law. Parentage without marriage is once legitimate when the infant is an adulterate and is discussed in the law books whose decree is brought in article 1167 of civil law. Due to the fact we deal with the parentage of illegitimate children and as we said in defining parentage that it is a natural and blood relationship between the child and the parents, it is imperative that the natural and blood relationship be established between the parents and the child of the adultery, so that one can recognize a definite parentage, though illegitimate for these children. Most importantly, theses children will come out of the bewilderment and confusion surrounding their identity recognition and their attribution to their own parents. Thus, in the second section, we address the illegitimate children parentage and we also, have a discussion on the waif to understand whether they're legitimate and to whom they could be attributed. 


\section{C) Paternal and maternal parentage of illegitimate children}

\section{Paternal parentage of illegitimate child}

There's no doubt with regards to the fact that an illegitimate infant is created out of his natural father and this infant is customarily and in language his own child. However, what matters, is that the lawmaker has not recognized this sort of parentage due to social interests and maintaining family interests, because $h$ has stipulated in article 11167 civil law that the child born of adultery is not returned to the adulterer. Here, in this discussion, we are not supposed to prove the legal and Sharia parentage of the illegitimate child, rather the fact that it is established that a child is created out of a man's semen, his attribution to the father will be easier. Thus, here, we deal first with the paternal parentage of the illegitimate child from the perspective of the Islamic jurisprudence and then we will discuss the civil law views on this point.

\section{THE PATERNAL PARENTAGE OF THE ILLEGITIMATE CHILD IN THE ISLAMIC JURISPRUDENCE}

In the Islamic law, parentage or the proper trample and uncertainty is established, where parentage out of adultery or in its decree uncertainty will not be established. The question arising is whether in this case, the parentage between adulterer and the child born of adultery will be nullified. The apparent theme of the scholars is the cancellation of parentage in this regard, i.e. parentage is abrogated between them because, and they have interpreted it as the lack of parentage thereby nullifying them. However, considering their words, indicates their interpretation disagreement, because some of the mandates of prohibition regarding the child born of adultery are established that they (adulterates) are created out of the semen of the couples, hence adulterates are called children in language. For example, a girl, born of adultery is barred to be given to the adulterers and if we nullify parentage generally we have just made a child out of their intermixed semen.

To the contrary, reality opposes this, unless we state the criterion is prohibition of that parentage and the child is truly established customarily. What is available in Rewayat (Imams' words) doesn't imply the cancellation of the parentage and lack of attribution to the parents. This, also, satisfies the accursed child, rather there are discussions about the lack of heredity and the like. The nullification of the mandate includes the nullification of the subject and if it is claimed the nullification of parentage is not only clear, but also, numerous in teachings, perchance it is because of the mutual necessity between the cancelled mandate and cancelled parentage where this mutual necessity is not clears either.

\section{1. The views of the Imamya scholars on the paternal parentage of the illegitimate child}

There are two views of the Imamya scholars regarding the attribution or nullification of the parentage among the Imamya scholars.

\section{A) Scholars believing in parentage nullification}

Most scholars nullify the parentage of adultery. In this regard, the author of Jawaher, states: "In any case, parentage caused by adultery is not established, rather it is possible to 
claim this issue is necessary, though in the teachings, lack of its establishments is clear and various. Thus, if a man commits adultery and an infant is created thereof, the infant is not legally attributed to hi. Neither wills this infant be attributed to his mother, so that other decrees are bound on them (Njafi, 1981). Also, the author of Ryaz has claimed of uncertainty with regards to the lack of the infant's attribution to his own father as he says," the effects of adultery is not established unless unanimously in the prohibition belonging to the parentage and the apparent words of scholars are just about the establishment of prohibition to parentage, rather there's widespread agreement towards it and that's argument" (Tabatabaee, 1980). The author of Masalek has maintained that parentage is not unanimously established with adultery. He was asked whether it was forbidden for an adulterer to marry a girl from whose semen she's created and an adulteress to marry a boy born of her?

He responded by saying that it is forbidden, since they're created out of their semen and are considered as their children and in language. Because in Arabic, child as a word (walad) is an animal born out of the semen of another peer animal and in adultery, the essence is based on the lack of parentage transference .In particular, the word implies the lack of establishing Sharia truth in adultery (Shahidsani, 1950).

These scholars have invoked a Rewayat with respect to the lack of attribution of the child to the adulterer:

Mohamad Ibn Sanan quoted Imam Reza (PBUH) responding to a problem as " God has prohibited adultery, due to the corruption in it, including manslaughter (soulkilling), elimination of parentage and lack of children nurturing as well as other aspects of corruption.

\section{B) Scholars believing in parentage attribution}

Some other Imamya scholars maintain that child born of adultery is returned to his own parents. Mamaghani in the book "Menhaj al-Motaghin" states" there is no difference between the acquisition of parentage in the proper parentage or uncertainty or adultery. Although other scholars have spoken of the lack of parentage establishment, we didn't find a reason for it. However, the main reason is the child of adultery is like the lawful child with respect to all the mandates of parentage except for inheritance and there is no inheritance between the child of adultery and his relatives and that's because of special wording. In other cases, evidence emphasizes on the lawfulness of the adulterate like the legitimate child, because in language and customarily he is a child and a brother. Also, late Bojnoordi says that the child of the semen holder is an evolution affair, because this child is created out of that semen himself, becoming a human in God's order. He is like cultivation when we cultivate a seed on earth, grown, and then becomes lavender. The semen after reaching the womb becomes grow able and then becomes a human. Of course, with regards to adultery, the judge has nullified this evolutionary attribution for some reasons and for some interprets. The main reason could be to save the society from disbelief. He quotes rewayat from Abi Jafar regarding a man committing adultery, making the woman pregnant then married he . After that a child was born and he was the most similar God' human to the father where the Imam said: a child born out of vain will not inherit.

\section{3. Views of the Sunnite scholars regarding the paternal parentage of the illegitimate child}

Sunnite scholars believe there is no parentage for the adulterer, because establishing parentage is favor and compensation is not established by favor, rather the holder of 
compensation is also the holder of retaliation. An adultery with which parentage is not established a deed void of any uncertainty will for forfeit limit and in case, there is uncertainty in adultery, the description of the compensation will be removed or forfeited. Should limit is forfeited, parentage will be established. However, if a person claims parentage towards someone who is like him and this person's parentage is not known, his parentage is established should he does not refrain to say it's caused by adultery. Some Sunnite scholars do not attribute the child born of adultery to the father, saying there is no relationship between father an the child. They claim the semen by which the child was created was outsider an thus m, the father could marry the child should it is a girl, as Shafeiy and Malek consider as permissible marriage with the girl of adultery, because she is outsider. They also claim her parentage is not legal and heredity cannot be established between them and more there is no alimony on them. However, Hanabele and Hanife have stated they're unlawful as legal daughters, because the one from whose semen they're created, they're habitually their daughter. Based on the verse" thy mothers and daughters are forbidden for you" this girl is the daughter of the adulterer created of this semen. This is a fact not different with lawful and unlawful and this daughter is a party of his body and is not lawful to him like a child born of marriage. According to the stated problems, it is concluded that there is no unanimous views among Muslim scholars with regards to the lack of the attribution of natural child to be father. As we said, some have attributed father-child rights excepting inheritance. While some other scholars call the child of adultery as outsider, believing in the lawfulness of marriage with her.

\section{4. Legal mandate of the paternal parentage of the illegal child}

Since the Iranian civil law adopt the Imamya jurisprudence, based on the views of the most of the Imamya scholars, the child of adultery is not returned to the adulterer. The Iranian civil law in article 1167 stipulates: that the adulterate is not attributed to the adulterer. Of course, here by attribution, it is legal attribution, not natural and customary attribution. Thus, given this article, the child born of adultery is not legally attributed to the adulterer and if father and mother are both adulterers, the child is not returned to either of them. Of course, based on the procedural unity verdict issued in 1997 (official paper), the father of the illegitimate child, though not his legal farther, is his natural father and possesses all the rights and duties, the father has against his child (except inheritance) and moreover, there is no difference between the legitimate and illegitimate child with respect to other rights and duties. If it is said the procedural unity verdict contradicts with article 1167 civil law, one can say what has been mentioned in the civil law article, regarding the lack of the adulterates' attribution to the adulterer is a legal and Sharia attribution. However, in the procedural unity verdict, the child is attributed to the natural father customarily and all the effects of the legitimate child except for inheritance are considered. Thus, we can say there is no contradiction between the procedural unity verdicts with article 1167 civil law. On the other hand, given this verdict, the father of the child, though illegitimate is bound to fulfill all the duties of his own child.

\section{5. Judicial basics of the procedural unity verdict of the supreme national court}

In 1997, the general board of the supreme national court issued a procedural unity verdict which was as a law to specify the legal status of illegitimate children. Because, this verdict was in accordance with the judicial decrees issues backed by judicial support. Let's explain briefly the judicial basics. The verdicts states as per, clause a, article 1, the personal 
status organization is to issue ID cards and birth dates. The lawmaker distinguishes no difference between children out of illegitimate and legitimate conception.

Provision of article 16 and article 17 of the mentioned laws have stipulated some conditions concerning cases where the marriage of father and mother is not resisted and there is no agreement as to the proclamation of birth and ID issuance or the fact that child's parents are unclear. However, when the child is adulterate and the adulterer doesn't plan to get the ID, using all the information of the mentioned article an d problems 3 and 47 of judicial regulations from the perspective of Imam Khomeini and the adulterer is regarded as the habitual father and as a result all the relevant duties and rights including getting the ID will be upon him and according to article 884 civil law, the mere fact of inheritance will be abolished between them.

\section{a) Lack of attribution of the illegitimate child to the habitual father}

Accordingly, the illegitimate child is not returned to either of the adulterer or the adulteress and only the marriage of adulterer or adulteress is an exception in the language of scholars. I other words, the adulterate having no legal relations with the adulterer or adulteress, their marriage together will be barred. To establish t5hat agreement and the truthfulness of the child are invoked. This viewpoint is famous for being a Fatwa as the author of Jawaher considers it unanimous and necessary, invoking the Ferash Hadith.

b) The attribution of illegitimate child to habitual father

c) Accordingly the adulterate will be returned to the adulterer or adulteress, only inheritance becomes a special wording mandate. The other verdicts of parentage are reserved for them.

Example: If a man commits adultery with a woman and a boy is born and then the boy maries the same woman and a boy is born thereof, though proper marriage, the older boy, since is of adultery receives no Habve whereas he is obliged to perform his father's prayers expired, because he's considered the legal and habitual son.

Of course, late Bojnoordi calls him legal child that can't be critical, because if he's a legal child, he should receive inheritance, while he himself says, Habve that is a kin $\backslash$ d of inheritance is not paid to him. Now the question is if the adulterate is in language returned to the adulterer, what reason can be brought he doesn't have parentage legally and is not returned to the adulterer? Can it be said that the term Valad (child) has been removed from its lexical meaning, finding another sense in the Shria? In other words, does the child have a Sharia reality?

The answer is negative, i.e. the child of the adultery is a child customarily, legally and in language, because the principle of the lack of conversion in wordings and lack of establishment of the Sharia reality with relation to the child will engender that parentage is established in adultery.

And one cannot say that the adulterer and adulteress have born a child as result of a crime and are allowed to desert the baby, having no responsibility against it while the alimony and custody be upon the shoulder of the others or the national treasury. Those who believe in the relationship between the illegitimate child and his habitual father have challenged the evidence of these people believe in the parentage nullification, arguing these people refer to two reasons. 


\section{A. Imamya scholars ' unanimity}

The author of Jawaher invokes the agreement obtained and transferable. It is obvious the agreement obtained by the author of Jawaher is transferable agreement for us. Thus the agreement is not idiomatic because the evidence of agreements parties is clear or probable at least and that is the Ferash hadith.

Secondly: Agreement be transferable or obtained is argument when discloser is innocent whose revelation becomes different if no impossible as stated in the principles. Thirdly: Imamya and popular scholars have agreed upon disinheritance and from their words, lack $\mathrm{f}$ parentage cannot be invoked, although many scholars have nullified parentage after canalling inheritance (Shahidsani, 1950). However, it can't be said all those nullifying inheritance have also rejected relationship.

\section{B. Honarable Hadith}

This hadith by the prophet (the child is returned to his father tough his mother is famous for adultery and it is not clear that to whom the child belongs)has no problem in terms of documentation and is famous among all Islamic sects, being genuine. However, it can be challenged in terms of implication, because the hadith is applicable in cases where the child is doubtful.

\section{Maternal parentage}

As stated in the previous section, the child born of adultery is not returned to his father legally, Now the question is if the child of adultery is not returned to his own mother either.

\section{Imamya opinion on the nullification of the illegitimate child's parentage with regards to mother}

Imamya scholars believe the adulterate is not returned and the evidence they cling to is some information that exists:

1. Abdulla Ibn Sannan quotes Imam Sadegh, answering a question to whom shall belong the inheritance of an adulterate, having parents. The Imam said his inheritance shall belong to the Imam.

2. Muhamad Ibn Hasan Ghomi quoted Abi Jafar when he was asked "a man has had intercourse with a woman, and then married her after the woman became pregnant. After an infant was born, very much similar to the man". Imam said the adulterate will not inherit.

Generally limam said that the child will not inherit and this includes heredity between him and his mother and as a result the adulterate will not be returned to the adulterate: This argument can be challenged for though Imam has said the adulterate won't inherit, this word is not absolute and only includes inheritance. In contrast, some other Imamya scholars maintain that the adulterate could be returned to his mother and the reason is a hadith of Imam Ali that the adulterate and the accursed child will inherit from his mother, maternal kinsmen, uncles and maternal aunts.

\section{The Sunnite scholars' opinion on the maternal parentage of the illegitimate child}

Popular jurists claim with regards to the parentage establishment o the part of mother that the maternal parentage is established by birth and does not hinge on another thing and there is no difference his birth is caused by property marriage or by corrupt marriage. 


\section{The legal mandate of the maternal parentage of the illegitimate child}

As stated previously, the adulterate is not returned to the adulterer. A group of people in accordance with this; law article have expressed that given the civil law, the adulterer has been named as the masculine noun and does not include women . Thus, the adulterate is not returned to his natural father, while it is returned to his mother and the legal relationship of parentage is established between this child and his mother with all the implications. However, this argu8ment has been challenged (Safaee and Emami, 1997), because first of all the feminine an masculine attribution are not equal and hence, the word adulterer can be applied for both man and woman since in Persian there is no grammatical difference between the word adulterer. Srcondly, It is clear from the civil law articles thatb the lawmaker has considered no difference between the adulterer and adulteress and ione can refer to the articles 1165, 1166 and 884, because according to articles 1165 and 1166 . Thus, the adulterate is not returned to his natural father, while it is returned to his mother and the legal relationship of parentage is established between this child and his mother with all the implications. However, this argument has been challenged because first of all the feminine an masculine attribution are not equal and hence, the word adulterer can be applied for both man and woman since in Persian there is no grammatical difference between the word adulterer.

\section{CONCLUSION}

Parentage which is the same blood and legal relationship relating parents to their children and has many types. Some of the Imamya scholars believe in the nullification of parentage referring to some hadith that exist in this relation. Some others attribute the adulterate to his own parents, believing in all rights and duties except inheritance/. Among the Sunnite scholars some attribute him to his father, believing in all the rights and duties for his except inheritance a some other scholars calm, this child as outsider, considering as lawful marrying this child. Regarding the adulterate to his mother, some Imamya scholars do not attribute him, while some others attribute him to his mother referring to a hadith of Imam Li whereas the Sunnis maintain that the maternal parentage is established by birth, not hinging on any thing else and there is no difference whether the child is out of proper marriage corrupt marriage.

\section{References}

[1] Emamai S. H. (1993). Civil law, Tehran: Islamya bookshop publication.

[2] Emami A. (1970). Comparative study of parentage in the Iranian and French law, Tehran: Tehran University publications.

[3] Fazillankarani Ayatola Sheikh M. (1998). Encyclopedia of judicial fatwa. Egypt publications.

[4] Ghahgheri S. M. (1963). Child abuse in Iran, Tehran: Ministry of culture and Islamic affairs publications.

[5] Karimi H. (1986). Judicial regulations from the perspective of Imam Khomeini, Ghom: Shokhi publications. 
[6] Katoozian N. (1993). Family law. Tehran: Tehran University Press.

[7] Najafi M. H. (1981). Jewelry Alklam. Beirut: Daral'hya, Altras Arabi.

[8] Safaee S. H., Emami A. (1995). The law of the family, Tehran: Tehran University publications.

[9] Shahidsani (1950). Alafham Msalk. Ghom: Islamic Institute Press.

[10] Tabatabaee S. A. (1980). Garden of issues. Tehran: Sangi publication. 